\title{
An Approach to Rank Noise Pollution in Workplaces
}

\author{
V. Franzitta ${ }^{1, a}$, A. Viola ${ }^{1, b}$, M. Trapanese ${ }^{1 \mathrm{c}}$, G. Ciulla ${ }^{1 \mathrm{~d}}$, V. Lo Brano ${ }^{1 \mathrm{e}}$. \\ ${ }^{1}$ DEIM - Dipartimento Di Energia, Ingegneria Dell'informazione, E Modelli Matematici, University of \\ Palermo, Palermo 90128, Italy \\ afranzitta@dream.unipa.it , balessia.viola@unipa.it, ${ }^{c}$ marco.trapanese@unipa.it, \\ dciullaina@dream.unipa.it, 'lobrano@dream.unipa.it
}

Keywords: workplace; noise; control; priority.

\begin{abstract}
In this paper, we describe a method for classifying the workplaces as regards the noise risk. This method provides an univocal classification of work area and allows to correctly implement the control measures in accordance with a suitable priority scale. Finally, this method can be easily adjusted to respect various national standards.
\end{abstract}

\section{Introduction}

Notwithstanding the negative effect of noise on workers is a well known effect, a universal approach to a general regulation on the maximum admissible exposure for workers has not yet been generally established[1-2]. Even the main international standard on the field ISO 1999:1990 explicitly states in its foreword that "the selection of maximum tolerable or maximum permissible noise exposures, and protection requirements as well as the selection of specific formulae for handicap risk assessment or compensation purpose require consideration of ethical, social, economic and political factors not amenable to international standardization" [3-4]. As a result, each nation enforces its own regulation and national standards are the main source for best-practices in acoustic design of workplaces. The lack of a general and standardized approach to the design of acoustic environment of working places has several negative consequences: for instance the noise emission of machinery and equipment must be adapted case by case to the national site of installation, the development of technical devices for noise reduction in working places is negatively influenced etc. The main internationally accepted concepts are Noise-Induced Permanent Threshold Shift (NIPTS) and the method for measurement of noise exposures.NIPTS is the precursor of NIHL (Noise Induced Hearing Loss) and the main consequence of occupational noise. It corresponds to a permanent increase in the threshold of hearing that may be accompanied by tinnitus. Because hearing impairment is usually gradual, the affected worker will not notice changes in hearing ability until a large threshold shift has occurred. Noise-induced hearing impairment occurs predominantly at higher frequencies $(3000-6000 \mathrm{~Hz})$, with the largest effect at $4000 \mathrm{~Hz}$. It is irreversible and increases in severity with continued exposure. This paper presents a method for ranking workplaces and working areas within a working place for noise control purposes. It is to be used when there are several noisy workplaces and a management decision must be made on the sequence of the implementation of noise control measures. This method, requires, first, a noise exposure survey to be performed and the average noise exposures, LTrade, of the various noise-exposed groups to be calculated using the procedure in the CSA Standard Z107.56 [2]. Then, noise exposures should be grouped into ranges (usually starting with $85 \mathrm{dBA}$ ). By using the LTrade and the number of noise-exposed workers in each range of noise exposures, four estimates are calculated. The ranking of the workplaces is then obtained by using the estimates individually or in combination. The mathematical tools used to develop this methodology are general and have been used in other field of sciences [5-14]. The paper is organized as follows after the introduction, in section 2 it is shown that a ranking procedure, based on the use of several indexes lead sometime to contradictory solution, in section 3 we propose an improved procedure and in section 4 we draw the conclusions. 


\section{A not-univocal ranking approach.}

An operative procedure for classifying the workplaces as regards the noise risk and deducing a sequence of the control measures provides some steps which are here summarized:

- To acquire a detailed information about the spatial and activity layout in such a way to individuate homogeneous work areas and attribute workgroups to the corresponding specific trades.

- To perform the experimental survey about the acoustical climate, determining in particular the average noise exposures of the workgroups (LTrade) according to the CSA Standard Z107.56 [2].

- To fix the ranges of noise exposure levels into which the measurement results have to be divide beginning from the risk minimum threshold.

- To distribute the total number of workers in each range at each work station.

- To calculate the "collective noise exposure" as the sum of the products of the number of workers in each trade times their LTrade.

- To calculate the average noise exposure level for each noise exposure range by dividing the collective noise exposure in each range by the number of workers within the same range.

- To calculate the normalised average noise exposure level by subtracting the risk minimum threshold from the average noise exposure level.

To individuate the maximum collective LTrade, which is defined as the collective noise exposure for the trade with the highest LTrade within each noise exposure range.

The value of $85 \mathrm{dBA}$ is correctly assumed as risk minimum threshold, as can be confirmed consulting the table reported in Recommendation ISO 1999 [3] about the percent risk of noise-induced permanent threshold shift (NIPTS) for noise exposition. Furthermore in most cases $90 \mathrm{dBA}$ is the limit at which engineering noise control is recommended, this level may be used as the upper limit. Therefore, the first range can be $85-90 \mathrm{dBA}$, the next can be 90-95 dBA, and so on.

In order to show the fact that the proposed procedure does not provides univocal solution we briefly resume the results of a study of three workstations with five trades each [1]. Table 1 contains data set as before specificated. Table 2 shows the total number of workers in each range at each station as well as the total number of workers with noise exposures falling in the ranges $<90 \mathrm{dBA}$ (that is $85-90$ $\mathrm{dBA}$ ), $>90 \mathrm{dBA},>85 \mathrm{dBA}$ (that is the sum of both).

Table 1. Data for the Three Stations. [1].

\begin{tabular}{|c|c|c|c|c|c|c|c|c|c|c|c|c|c|c|}
\hline \multirow[b]{2}{*}{ Station } & \multicolumn{5}{|c|}{$<90$ dBA } & \multicolumn{5}{|c|}{$>90 \mathrm{dBA}$} & \multicolumn{4}{|c|}{$>85 \mathrm{dBA}$} \\
\hline & 1 & 2 & 3 & 4 & 5 & 1 & 2 & 3 & 4 & 5 & 1 & 2 & 3 & 4 \\
\hline $\mathrm{A}$ & 17 & 14530 & 85 & 0 & 6880 & 150 & 14125 & 94 & 9 & 4850 & 320 & 28655 & 90 & 5 \\
\hline B & 0 & 19706 & 86 & 1 & 1070 & 134 & 12862 & 96 & 11 & 9700 & 362 & 32568 & 90 & 5 \\
\hline $\mathrm{C}$ & 22 & 21875 & 86 & 1 & 1 & 150 & 13760 & 92 & 7 & 1900 & 405 & 35635 & 88 & 3 \\
\hline & 8 & & & & 8700 & & & & & & & & & \\
\hline & 25 & & & & & & & & & & & & & \\
\hline & 5 & & & & & & & & & & & & & \\
\hline
\end{tabular}

The workplace ranking mentioned method considers four estimates which can be individually or in combination: 1) number of workers within the ranges of noise exposures, 2) collective noise exposure, 3) Average noise exposure 4) normalized noise exposure, 4) maximum collective LTrade.

The normalized average noise exposure level is obtained by subtracting $85 \mathrm{dBA}$ (accepted as a "safe" limit) from average noise exposure level. This is done to enhance differences between noise exposure levels from the workplaces, it can also be used as an estimate of the risk of hearing loss. With reference to the application reported in the Tables 1 and 2, we obtain the picture of Table 3 . 
We can find the sequence suggested by each estimate for the consequent control measures. The decision on where to start depends on the choice of parameter: if noise exposure of the $>90 \mathrm{dBA}$ range is the decisive factor, then station $\mathrm{A}$ should be the first to be treated, then $\mathrm{C}$ stations and $\mathrm{B}$. If, however, the collective noise exposure of all workers is the parameter of choice, then the ranking should be stations $\mathrm{C}, \mathrm{B}$ and $\mathrm{A}$, the same as if parameter $<90 \mathrm{dBA}$ was chosen.

Table 2. Combined Data. Source: [1]

\begin{tabular}{|c|c|c|c|c|c|c|c|c|c|}
\hline Trade & \multicolumn{3}{|c|}{ Station A } & \multicolumn{3}{|c|}{ Station B } & \multicolumn{3}{|c|}{ Station C } \\
\hline & $\begin{array}{l}\text { Workers in } \\
\text { the trade }\end{array}$ & $\begin{array}{c}\mathrm{L}_{\text {Trade }} \\
\text { [dBA] }\end{array}$ & $\begin{array}{c}\text { Collective } \\
\text { noise } \\
\text { exposure }\end{array}$ & $\begin{array}{l}\text { Workers in } \\
\text { the trade }\end{array}$ & $\begin{array}{c}\mathrm{L}_{\text {Trade }} \\
\text { [dBA] }\end{array}$ & $\begin{array}{c}\text { Collective } \\
\text { noise } \\
\text { exposure }\end{array}$ & $\begin{array}{l}\text { Workers in } \\
\text { the trade }\end{array}$ & $\begin{array}{c}\mathrm{L}_{\text {Trade }} \\
{[\mathrm{dBA}]}\end{array}$ & $\begin{array}{l}\text { Collective } \\
\text { noise } \\
\text { exposure }\end{array}$ \\
\hline $\mathrm{I}$ & 20 & 95 & 2375 & 34 & 93 & 3162 & 155 & 85 & 13175 \\
\hline II & 50 & 97 & 4850 & 25 & 85 & 2125 & 100 & 87 & 8700 \\
\hline III & 75 & 92 & 6900 & 100 & 97 & 9700 & 50 & 90 & 4500 \\
\hline IV & 90 & 85 & 7650 & 80 & 86 & 6880 & 80 & 92 & 7360 \\
\hline V & 80 & 86 & 6880 & 123 & 87 & 10701 & 20 & 95 & 1900 \\
\hline Totals & 320 & & 28655 & 362 & & 32568 & 405 & & 35635 \\
\hline
\end{tabular}

Table 3. Ranking of Estimates

\begin{tabular}{|c|c|c|c|c|}
\hline Estimate & Range & First & Second & Third \\
\hline \multirow{3}{*}{$\begin{array}{l}\text { Number of workers } \\
\text { within the range }\end{array}$} & $<90 \mathrm{dBA}$ & $\mathrm{C}$ & $\mathrm{B}$ & A \\
\hline & $>90 \mathrm{dBA}$ & $\mathrm{C}$ or $\mathrm{A}$ & & $\mathrm{B}$ \\
\hline & Total & $\mathrm{C}$ & $\mathrm{B}$ & $\mathrm{A}$ \\
\hline \multirow{3}{*}{$\begin{array}{l}\text { Collective noise } \\
\text { exposure }\end{array}$} & $<90 \mathrm{dBA}$ & $\mathrm{C}$ & B & A \\
\hline & $>90 \mathrm{dBA}$ & A & $\mathrm{C}$ & $\mathrm{B}$ \\
\hline & Total & $\mathrm{C}$ & $\mathrm{B}$ & $\mathrm{A}$ \\
\hline \multirow{3}{*}{$\begin{array}{c}\text { Normalised noise } \\
\text { exposure }\end{array}$} & $<90 \mathrm{dBA}$ & $\mathrm{B}$ or $\mathrm{C}$ & & A \\
\hline & $>90 \mathrm{dBA}$ & $\mathrm{B}$ & $\mathrm{A}$ & $\mathrm{C}$ \\
\hline & Total & $\mathrm{A}$ or $\mathrm{B}$ & & $\mathrm{C}$ \\
\hline \multirow{2}{*}{$\begin{array}{l}\text { Maximum collective } \\
\qquad L_{\text {Trade }} .\end{array}$} & $<90 \mathrm{dBA}$ & $\mathrm{B}$ & $\mathrm{C}$ & $\mathrm{A}$ \\
\hline & $>90 \mathrm{dBA}$ & $\mathrm{B}$ & A & $\mathrm{C}$ \\
\hline
\end{tabular}

\section{An improved procedure.}

Analyzing the content of the above Table 3 it appears, that the use of the four estimates is not always straightforward. If the ranking orders using each of estimates are the same, the ranking is obvious, but in situation more complicated like situation above mentioned the optimum solution cannot be easily found.[15-16]

This result stimulates some remarks:

- Information linked to number of workers within the range, average noise exposure of the workgroups LTrade and Normalized Average Noise Exposure Level NANEL is basic when a priority scale has been setting up. The aforesaid indicators, in fact, express influence basin and entity of the noise risk problem.

- The first two parameters, indeed, are well synthesised by the resulting collective noise exposure CNE.

- The maximum collective LTrade seems more relevant when the decision process faces in detail the single trades for each workstation. 
Then we propose to assume as a unique estimate the following descriptor that here is called priority index:

\section{$\mathrm{PI}=\mathrm{NANEL} * \mathrm{CNE}$}

that we retain both conceptually founded and better adequate to reach the proposed target that is a clear and unambiguous classification. This last statement is evident from the Tables 4 and 5 which report the obtained results applying the expression (1) to the example before described. In Table 4 the index PI is calculated by multiplying the values in column 2 times the values in column 4 .

Table 4. Combined Data in the present application.

\begin{tabular}{|c|c|c|c|c|c|c|c|c|c|c|c|c|c|c|c|}
\hline \multirow[b]{2}{*}{ Station } & \multicolumn{5}{|c|}{$<90 \mathrm{dBA}$} & \multicolumn{5}{|c|}{$>90 \mathrm{dBA}$} & \multicolumn{5}{|c|}{$>85 \mathrm{dBA}$} \\
\hline & 1 & 2 & 3 & 4 & PI & 1 & 2 & 3 & 4 & PI & 1 & 2 & 3 & 4 & PI \\
\hline A & 170 & 14530 & 85 & 0 & 0 & 150 & 14125 & 94 & 9 & 127125 & 320 & 28655 & 90 & 5 & 143275 \\
\hline B & 228 & 19706 & 86 & 1 & 19706 & 134 & 12862 & 96 & 11 & 141482 & 362 & 32568 & 90 & 5 & 162840 \\
\hline $\mathrm{C}$ & 255 & 21875 & 86 & 1 & 21875 & 150 & 13760 & 92 & 7 & 96320 & 405 & 35635 & 88 & 3 & 106905 \\
\hline
\end{tabular}

The results for PI showed in Table 4 simply allow to execute the ranking in Table 5 that is univocal (first B, second A, third C) and different from that guided by the Behar's method.

Table 5. Ranking of Estimates

\begin{tabular}{|c|c|c|c|c|}
\hline Estimate Criterion & Range & First & Second & Third \\
\hline \multirow{3}{*}{ Priority Index PI } & $<90 \mathrm{dBA}$ & $\mathrm{C}$ & $\mathrm{B}$ & $\mathrm{A}$ \\
\cline { 2 - 5 } & $>90 \mathrm{dBA}$ & $\mathrm{B}$ & $\mathrm{A}$ & $\mathrm{C}$ \\
\cline { 2 - 5 } & Total & $\mathrm{B}$ & $\mathrm{A}$ & $\mathrm{C}$ \\
\hline
\end{tabular}

At this point it is to note that in order to adjust the proposed methodology to Italian national standards, we can substitute the average noise exposure of the workgroups LTrade with the personal or group exposition level PEL obtained from the definition and operative criteria contained in the Italian rule n.277/91 [4] that accomplishes precise UE directives. The same approach can be followed for any national standards.

\section{Conclusions}

In this paper, a method for classifying the workplaces as regards to the noise risk and correctly implementing the control measures in accordance with a suitable priority scale is shown. This method has been developed from a primary procedure essentially for minimising the uncertainty in decision process. The method based on some general mathematical techniques used in other field of sciences appears to be robust and easy to be used in the decision process which aims to enhance safety in workplaces gives good results. The method is flexible and an fulfill the requirements of most existing national standards.

\section{Acknowledgment.}

This work was funded by Ministero dell` Ambiente e Del Mare through IMPETUS project.

\section{References}

[1] Behar, A.; Comparison of Noise Exposure Levels between Workplaces. Appl. Acoustics 37,4 1992, 325-331.

[2] Canadian Standard Association, CSA-Z107.56: Procedures for the measurement of occupational noise exposure. Canadian Standard Association, Toronto, Ontario, Canada, 1980.

[3] Recommendation ISO 1999 (1990) "Acoustics - Determination of occupational noise exposure and estimation of noise-induced hearing impairment. 
[4] Decreto n.277, 15 agosto 1991, Attuazione delle direttive 80/1107/CEE, 82/605/CEE, 83/477/CEE, 86/188/CEE e 88/642/CEE in materia di protezione dei lavoratori contro i rischi derivanti da esposizione ad agenti chimici, fisici e biologici durante il lavoro, a norma dell'art. 7 della legge 30 luglio 1990, n. 212. (G.U. 27-8-1991, n. 200 - suppl.).

[5] Franzitta, V., Rizzo, G.. - Renewable energy sources: A mediterranean perspective. ICBEE 2010-2nd International Conference on Chemical, Biological and Environmental Engineering, Proceedings, p.48-51, art. no. 5652332 (2010).

[6] Bonanno, A., Franzitta, V., Muzio, F.P., Trapanese, M. - A multiphysics approach to the design of a seawave energy conversion system. Proceedings of ICSET, Singapore, 2008,p.p. 665 668 ,art. no. 4747090

[7] Di Dio, V., Franzitta, V., Muzio, F., Scaccianoce, G., Trapanese, M. - The use of sea waves for generation of electrical energy and hydrogen. MTS/IEEE Biloxi - Marine Technology for Our Future: Global and Local Challenges, OCEANS, 2009, art. no. 5422319.

[8] Sorrentino, G., Scaccianoce, G., Morale, M., Franzitta, V. The importance of reliable climatic data in the energy evaluation. Energy 2012.

[9] Trapanese, M., Viola, A., Franzitta, V. Description of hysteresis of nickel metal hybride battery. IECON 2012, 38th Annual Conference on IEEE Industrial Electronics Society, Montreal, Canada, pp. 967-970.

[10] Franzitta, V., Viola A., Trapanese M.; Description of hysteresis in Lithium battery by classical Preisach model, Advanced Materials Research Vols. 622-623 (2013) pp 1099-1103.

[11] Ciulla G., Franzitta V.; Lo Brano V., Viola A., Trapanese M., Mini Wind Plant to Power Telecommunication Systems: a Case Study in Sicily, Advanced Materials Research Vols. 622-623 (2013) pp 1078-1083.

[12] Trapanese M., A model of a linear synchronous motor based on distribution theory, J App Phys, Vol.111 (2012), Article number07E731.

[13] Trapanese M, "Noise enhanced stability in magnetic systems", J. App. PhysVolume 105, Issue 7, 2009, Article number 07D313.

[14] Cirrincione M., Miceli R., Galluzzo G.R., M. Trapanese, Preisach function identification by neural networks, IEEE Transactions on Magnetics Volume 38, Issue 5 I, (2002), Pages 2421-2423

[15]Franzitta, V., La Gennusa, M. , Peri, G., Rizzo, G., Scaccianoce, G.. Toward a European Eco-label brand for residential buildings: Holistic or by-components approaches?. Energy Volume 36, Issue 4, (2011), pp 1884-1892

[16] Trapanese M.; Franzitta V., Viola A. The Jiles Atherton Model for Description Of Hysteresis in Lithium Battery. Conference Proceedings - IEEE Applied Power Electronics Conference and Exposition - APEC 2013- Long Beach,(CA), March 2013-978-1-4673-4355-8, pp 2773-2775. 